\title{
Perceptions of organizational injustice in French business schools
}

\author{
Lovasoa Ramboarisata ${ }^{1}$, Linda Ben Fekih Aissi ${ }^{2}$
}

${ }^{1}$ École des sciences de la gestion, Université du Québec à Montréal, Canada, ${ }^{2}$ Laboratoire THEMA UMR CNRS 8184 CY Cergy Paris Université, France.

\begin{abstract}
Whereas the institutional drivers of the accountability discourse and the apparatus of performance evaluation accompanying such a discourse in the neoliberal university are well documented, their implications at the individual level have received lesser interest. Our paper suggests that more attention be paid to the voices and the experiences of the "governed". It accounts of the unfairness of the accountability regime in higher education, and more specifically in business schools, as it is perceived by scholars in France. Using insights from the institutional complexity (IC) and organizational justice (OJ) literatures, as well as an empirical analysis of the French business scholars'take on their changing work context and the metrics against which their performance is assessed, our study extends the understanding of the implications of organizations' rewards, incentives, performance control and evaluation practices for OJ. Moreover, it deconstructs the narrative of the accountability regime by reminding that institutional complexity leaves very little room for many scholars to be star researchers, excellent program managers, innovative and inclusive pedagogues as well as impactful public servants at the same time without hindering other academic missions they value (disinterested collegiality, care, social inclusion), their quality of life, family, and or health.
\end{abstract}

Keywords: business schools, accountability, organizational justice, scholars, evaluation, neoliberal university 


\section{Introduction}

The narrowly defined stereotype of the excellent scholar as both a star researcher and a successful manager of a flagship graduate program has compelling implications for academic culture, scholars' legitimacy and self-representation, the labour of academia, professoral career trajectory, and well-being in the academic workplace. The excellent scholar is praised for her or his impacts. In the business discipline, which is the focus of this paper, the stardom in research and outreach is proxied by the number of publications in highly-ranked reviews (most of which publish exclusively in English), number of citations, research grants received, international mobility, and research contracts with public and industrial partners. The excellence as a program manager is assessed against performance indicators such as the number of accreditations obtained by the program and or the school, a favourable position on the ranking system (for example, the famous Financial Times' MBA ranking), successful implementation of the program at international campuses, which are all variables for lucrativity. Whereas the institutional factors (for example, the globalization of education, the decrease in higher education organizations' public funding, the growing competition between universities, and the "dictatorship" of the ranking systems) that drive those expectations have been well documented, their implications at the organizational level (the university, the faculty or school) and the individual one (the scholar) have received lesser interest. We suggest that more attention be paid to the voices and the experiences of the "governed", the scholars who have to cope with the abovedescribed appraisal logics and processes. There are grounds for caution about the rapid and invasive diffusion of this dominant narrative about how the scholar's road map to excellence should look like. Results of a recent study by Wellcome Foundation and the research consultance firm Shift Learning (2020:3) revealed that : "Researchers say that their working culture is best when it is collaborative, inclusive, supportive and creative, when researchers are given time to focus on their research priorities, when leadership is transparent and open, and when individuals have a sense of safety and security. (...) While most researchers feel that their sector is producing high-quality outputs, they also report deep concerns about how sustainable the culture is in the long term. They say that conditions are being worsened by a complex network of incentives from government, funders and institutions that seem to focus on quantity of outputs, and narrow concepts of 'impact', rather than on real quality. The upshot is that they feel intense pressure to publish, with too little value placed on how results are achieved and the human costs." . While the sample used was UK-based, the study's findings echo earlier concerns about the terrorizing impact of the globalized university's performance evaluation and the discourse of accountability on scholars in other European and international higher education settings. Our paper discusses the unfairness of the accountability regime in higher education, and more specifically in business schools and faculties, as it is perceived by scholars in France. 
First we review the main attributes of the accountability regime. Thereafter, we briefly describe the conceptual framework, then the methodology of our study. This is followed by the presentation of the main findings. We conclude by outlining their implications.

\section{The accountability regime}

The accountability regime is characterized by an attitude that "prizes results", normative apparatus and a broader range of devices associated with the "new public management", which have come to define "true accountability" (Rouillard and Giroux, 2005). The latter have stimulated the pursuit of action understood as the cornerstone of efficient practice and the imperative for periodic assessment and highly visible justification. How it has influenced teaching and research in the whole university is explained by Sulkowski (2016: 10) as follows: "What dominates is the view of university transformation into a business market organization, executing the concept of 'new public management' (...), universities become 'producers' of educational services in a competitive market. This applies as well, and more fiercely, to teaching students, but equally to research performed by academics." It coincides with (or is considered by many observers as the consequence of the decrease in governments' financial commitment to higher education. Universities' performances are mainly defined by their economic relevance, as the so-called "knowledge-economy" objective has become part of the competitiveness agenda of many governments. Universities have hence been pushed to become "entrepreneurial" (Ramboarisata, 2016). As Mautner (2005: 96) puts it: "The social, political, and educational context in which they have moved centre-stage is a complex mesh of trends including the reduction of government funding, the consequent necessity to raise money from external, frequently corporate, sources, deregulation, increased competition and internationalisation, and the replacement of collegial by managerial (or, as critics would have it, managerialist) governance structures."

\section{Conceptual framework}

Two concepts are central to our analysis: institutional complexity (IC) and organizational justice (OJ).

As academic capitalism has gained ground, sustained by the diffusion of the accountability discourse in more and more regions and scientific disciplines, the logics pertaining the academic and social missions of universities (such as higher education as a public good, academic freedom, disinterested collegiality) have to co-exist with the market logics. This encounter entails a competition rather than a natural fit. Higher education organizations and scholars feel pressured to cope with these multiple and very often contradictory logics. Adaptation (and even resistance) efforts have become uneasy and paramount. This situation epitomizes what is known in Organizational Studies as institutional complexity (IC). IC 
researchers (Greenwood et al., 2010; Pache and Santos, 2010 ; Greenwood et al., 2011) argued that organizations and their members acquiesce to these logics in order to gain legitimacy and to obtain or maintain resources.

Recently published autoethnographies, collective autoethnographies and other qualitative accounts of scholars' evaluation conditions and experiences within the marketized university - also known as the corporatized or the neoliberal university - (see for example the special issue of the review Ephemera in 2017 untitled "The labour of academia") as well as calls to reflect on and write about the academic responses to the corporate culture in higher education (see for example the call for papers, launched in 2019 , for a special issue of the review Management and Learning untitled "The performative university - Targets and terror in academia: Implications for learning in business and management context") suggest that there is an issue of organizational injustice within the higher education context. Organizational justice (OJ) is a concept used to refer to the perception by individuals that they are fairly treated at work (Colquitt et al., 2001 ; Skarlicki et Folger, 1997 ; Adams, 1967). Injustice issue arises when the conditions for OJ are absent or violated. In the context of higher education transformations and the imperialism of the accountability regime, injustice has been signaled as more and more scholars are critical of the "narrow way in which their work is judged and valued, and what might be seen as an encroachment on academic freedom and the Weberian notions of vocation" (Robinson et al., 2017: 483).

Our study extends the understanding of the implications of organizations' rewards, incentives, performance control and evaluation practices for OJ. It does so by exploring an overlooked $^{1}$ sector, higher education. Moreover, it deconstructs the narrative of the accountability regime by reminding that institutional complexity leaves very little room for many scholars to be star researchers, excellent program managers, innovative and inclusive pedagogues and well as impactful public servants.

\section{Methodology}

We chose to focus on the case of French business scholars for a certain number of reasons. First, it was a convenient choice, as both authors use French as work language and one is based in France. Both belong also to the business discipline. Beyond convenience though, our choice was motivated by our own observations (and those of others) that the corporatization of French universities and business schools represent a much more radical change when compared to what occurred in other settings. With its tradition of coordinated

\footnotetext{
${ }^{1}$ The links between workers' performance evaluation and justice in commercial businesses enjoyed much discussion and empirical studies (see Aissi and Neveu, 2015, for a review of the literature).
} 
economy (versus the liberal-market economy of UK and US), characterized by collectivist governance and solidarity, France used to favor public funding for its higher education sector. Accountability-and-market-driven reforms such as La loi relative aux libertés et responsabilités des universities adopted in 2007 and the very controversial Loi de programmation pluriannuelle de la recherche, the adoption of which is imminent, force a break-up with the traditional ideals. From the point of view of IC, the French case is thus a very interesting one since the degree of contradiction between logics is high. Our particular interest for the business discipline can also be explained by the fact that it (and its schools) have been much more favourable than any other in internalizing those imperatives of accountability and the audit culture as well as the logics of the market; although academic capitalism has affected the management of the whole university. Globalization has accelerated business schools' path toward meeting their market-focused objectives via an intensification of offshore and online programs' offerings (Parker and Guthrie, 2010). Hence, in major business schools' setting, the new accountability ethos has promoted practices the main legitimacy challenge of which is to create new revenue streams and to improve cost-efficiency, the bottom line, and image (Starkey and Tiratsoo, 2007). On the research side, as Butler et al. put it (2017: 468) "These trends suggest that the Humboldtian idea of the university - which measures the value of scientific-philosophical knowledge (Wissenschaft) according to the degree of cultivation (Bildung) it produces - has been superseded by a regime based on journal rankings, citation rates, impact factors and other quantitative metrics used to assess and reward research 'output' (Lucas, 2006)."

Using text analysis and the protocol of grounded theory applied in the study of organizationa, we conducted a two-level-exploration which respectively aims at:

Assessing institutional complexity, which characterizes the setting of French business schools. More precisely, the study identifies the main institutional actors, the main interests at play and the contradictory expectations they impose one scholars.

- $\quad$ Examining traces of organizational injustice as perceived by the scholars.

Our documentary sources include governmental policies, publications by accreditation agencies presenting their assessment methods, study reports and position papers published by the French business schools and faculties' institutional stakeholders (the CGE which is the association of business schools, the CPU which is the association of universities' chancellors, and the FNEGE which is the largest and most influential foundation in the French business scholarship). That first set of documents enabled us to explore the dominant discourses at the institutional level. A second set of documents from which we gathered information includes a total of 263 articles and video-interviews retrieved from the websites of The Conversation France and XERFI Canal. These two outlets are used by French-speanking scholars for scientific vulgarization and (more and more) for activist communications. During the period of our study (2017-2019), there was a hiking number of 
articles and interviews about the transformations of French higher education and their impacts on research productions and producers as well as on teaching activities. Those data allowed us to inquire about the French scholars'take on their changing work context and the metrics against which their performance is assessed.

\section{Findings}

Symbolic and cultural institutions in academia, which are often from internal and sociohistoric sources (for example, regional and linguistic aspirations, the scientific community, individual scholars) and the logics they value (such as autonomy of thought, plurality of perspectives, ethics, disinterested collegiality, social inclusion, emancipation, and public service) have been strongly destabilized, even alienated, by the market logics carried from the external environment by regulative and normative institutions. The latter, as shown in table 1 below, are framing the definition and traits of what should be an excellent school and an excellent scholar. Their interests and expectations (especially, those of the regulators and normative actors such as the accreditation bodies) seem attractive to universtities' and schools' managers in the current context of resource scarcity and national competitive strategy-building. Nevertheless, as these expectations tend to overvalue the income-bearing dimension and outcome-focus of academic activities, regardless of the implications of such a choice on the scholars' work organization and on the symbolic and cultural institutions mentioned above, they end up creating tensions at the organizational and individual levels. The French business scholars and their organization are thus facing a significant institutional complexity.

Given such a complexity, the scholars are obliged to make a choice. Some acquiesce to the dominant external pressures, at the cost of abandoning traditional academic values. Some other, beholding to the principles of public service (teaching at the undergraduate level versus serving the "customers", which is often the status of the students of flagship programs in campuses located overseas) and socially-relevant research (which often demand conducting complex projects versus multiplying publications at high frequency) let go of the stardom and may suffer from marginalization and anxiety. A few try to abide by the contradicting pressures at the cost of their quality of life, family, and health. This situation creates (or enhance pre-existing) organizational injustice. Table 2 provides a portrait of the practices which French business scholars consider unfair by violating distributive, procedural, and interactional justices. 
Table 1. Institutional context of the French business schools

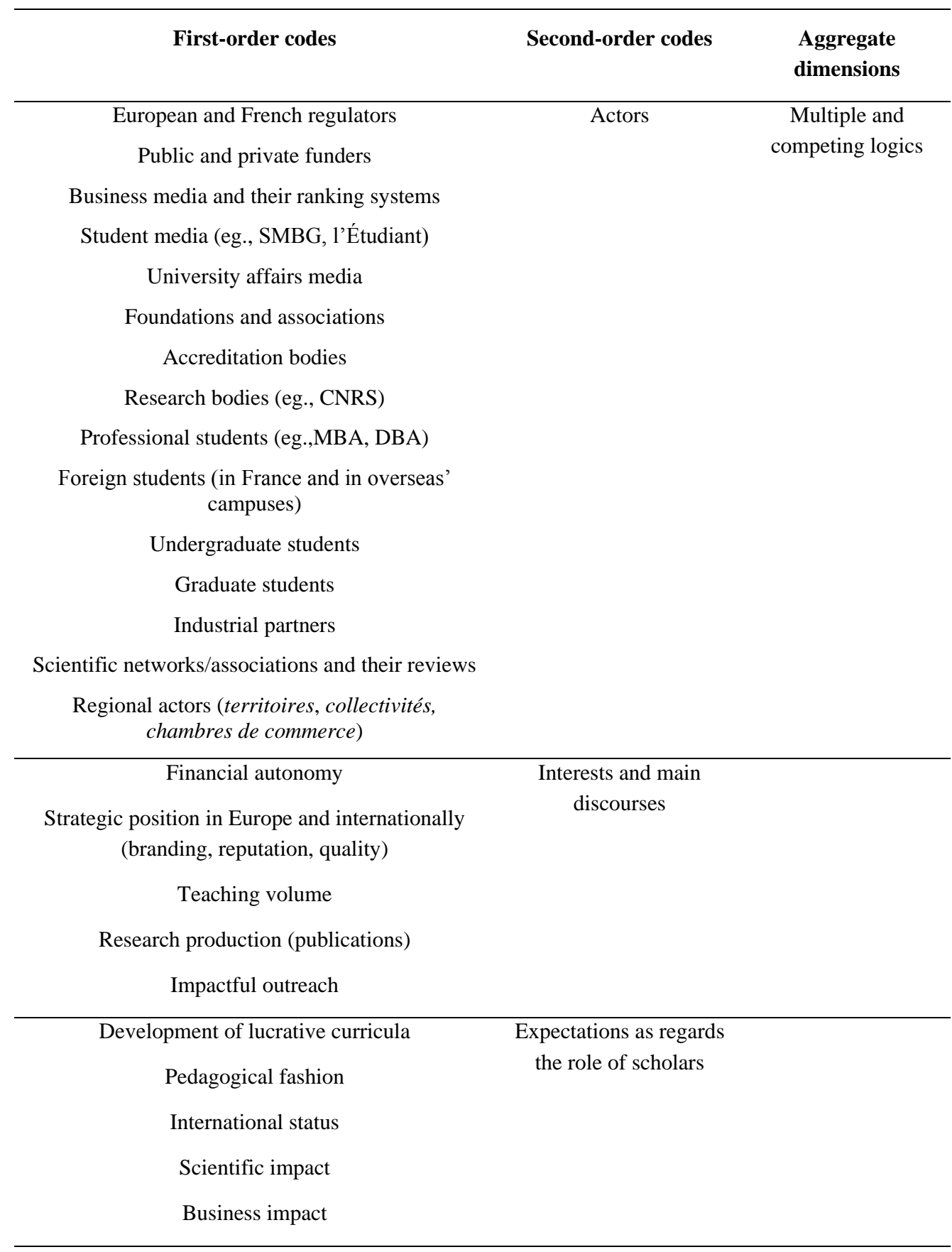


Table 2. Perception of organizational injustice by French business scholars

\begin{tabular}{ccc}
\hline First-order codes & Second-order codes & $\begin{array}{c}\text { Aggregate } \\
\text { dimensions }\end{array}$ \\
\hline $\begin{array}{c}\text { Activities are not valued fairly (eg., publishing } \\
\text { frequently vs. conducting a complex research } \\
\text { project; managing a research center vs. } \\
\text { managing a department; teaching at the } \\
\text { undergraduate level vs. teaching at the graduate } \\
\text { level; teaching in MBA vs. teaching in Msc.; } \\
\text { supervising students' research vs. partnering } \\
\text { with industrial actors) }\end{array}$ & $\begin{array}{c}\text { Perception of } \\
\text { injustice }\end{array}$ \\
$\begin{array}{c}\text { Unequal repartition of tasks between colleagues } \\
\text { promotion }\end{array}$ & Procedural \\
\hline Processes and criteria of hiring, tenure, and \\
Lack of respect for academic freedom \\
Lack of support when confronted with \\
out, etc.)
\end{tabular}

Among the frequently-mentioned drawbacks of those practices are the following. They promote only one model of professorship and only a certain type of research production and diffusion. They put scholars into fierce competition with each other. They are enforced with a paternalistic approach, and are gender-biased. They do not respect the professional nature of the status of professor.

\section{Concluding remarks}

The commodification of higher education and the unfair nature of the accountability regime and the evaluation system it imposes on scholars have been much criticized. Beyond shaming, outrage, suspicion, and lamentation though- which we think are necessary parts of a collective soul-searching -, it has become imperative to support this whistleblowing endeavour with evidence from empirical research exposing the negative externalities of the 
corporatization of universities and business schools from different parts of the world ${ }^{2}$. By conceptualizing business schools as a field of tensions and accountability university as a discourse, our paper raises awarness about the relevance and legitimacy of other existing but overlooked meanings (yet pre-existing) responsibility of higher education organizations.

\section{References}

Adams, J.S. (1965). Inequity in social exchange, in L. Berkowitz (dir.), Advances in Experimental Psychology, (267-299), New York : Academic Press.

Aissi, L.B.F., Neveu, V. (2015). Mieux comprendre les caractéristiques d'un monitoring électroniques acceptables par les salariés, à la lumière des théories de la justice organisationnelle, Revue de Gestion des Ressources Humaines, 3(97), 39-57.

Butler, N., Delaney, H. \& M. Slywa (ed.) (2017). Special Issue "The Labour of academia", Ephemera: Theory and Politics in Organization, 17(3).

Colquitt, J.A., Conlon, D.E., Wesson, M.J., Porter, C.O.L.H, Ng, K.Y. (2001). Justice at the millenium: A meta-analytical review of 25 years of organizational justice research, Journal of Applied Psychology, 86, 425-445.

Greenwood, R. Diaz, A.M., Li, X.S., \& Lorente, J.C. (2010). The multiplicity of institutional logics and the heterogeneity of organizational responses. Organization Science, 2, 521-539.

Greenwood, R., Raynard, M., Kodeih, F., Micelotta, E. R., Lounsbury, M. (2011). Institutional complexity and organizational responses, The Academy of Management Annals, 5(1), 317-371.

Mautner G. 2005. The entrepreneurial university. A discursive profile of a higher education buzzword, Critical Discourse Studies, 2 (2), 95-120.

Pache, A.-C., Santos, F. (2013). Inside the Hybrid Organization: Selective Coupling as a response to competing institutional logics , Academy of Management Journal, 56(4), 972-1001.

Parker, L.D. and Guthrie, J. 2010. Business schools in an age of globalization, Accounting, Auditing, and Accountability, 23(1), 5-13.

Robinson, S., Ratle, O., Bristow, S. (2017). Labour pains: Staring a career within the neoliberal university. Ephemera, 17(3), 485-508.

Rouillard, C. and Giroux, D. (2005). Public Administration and the Managerialist Fervour for Values and Ethics: Of Collective Confusion in Control Societies", Administrative Theory \& Praxis, 27(2),330-357.

Skarlicki, D.P., Folger, R. (1997). Retaliation in the workplace : The role of distributive, procedural, and interactional justice, Journal of Applied Psychology, 82, 434-443.

Starkey K. and Tiratsoo, N. 2007. The Business School and the Bottom Line. Cambridge University Press.

\footnotetext{
${ }^{2}$ Prior studies about the effects of the managerialization of business schools are mostly UK-based.
} 
Slaughter, S.; Leslie, Larry L. (1997). Academic Capitalism: Politics, Policies, and the Entrepreneurial University. The Johns Hopkins University Press.

Sulkowski, L. 2016. Accountability of university: Transition of public higher education, Entrepreneurial Business and Economics Review, 4(1), 9-21.

Wellcome Foundation and Shift Learning (2020). What researchers think about the culture they work in. London. (https://wellcome.ac.uk/sites/default/files/what-researchers-thinkabout-the-culture-they-work-in.pdf) 